\title{
When is a Reminder Enough? Text Message Voter Mobilization in a European Context
}

\author{
Johannes Bergh ${ }^{1} \cdot$ Dag Arne Christensen ${ }^{2} \cdot$ Richard E. Matland $^{3}$
}

Published online: 15 November 2019

(C) The Author(s) 2019

\begin{abstract}
Sending text messages reminding people to vote has only been examined as a mobilization tool in three studies, two of them done in the United States. The results from these studies are mixed. We investigate this tool's effectiveness using a field experiment in a different context, municipal elections in Norway. We find strong mobilization effects among groups traditionally low in participation (immigrants and youth voters). Young native Norwegians show an intent-to-treat (ITT) effect of $4.58 \%$ points, foreign nationals who have recently established Norwegian residency show an ITT effect of $2.93 \%$ points, and among immigrants who have lived in Norway for 7 years or more the treatment effect is $2.7 \%$ points. Even among native Norwegian voters over 30 , with a baseline turnout of $73 \%$, text messages generate a $0.96 \%$ points increase in turnout.
\end{abstract}

Keywords GOTV $\cdot$ Experiments $\cdot$ Turnout $\cdot$ Text messages $\cdot$ Nudging $\cdot$ Noticeable reminder theory

\section{Introduction}

Research on the use of SMS text messages as a voter mobilization tool has led to the formulation of the Noticeable Reminder Theory (Dale and Strauss 2009). The theory's premise is that registered voters generally have the intention to vote, but

Electronic supplementary material The online version of this article (https://doi.org/10.1007/s1110 9-019-09578-1) contains supplementary material, which is available to authorized users.

Johannes Bergh

johannes.bergh@samfunnsforskning.no

Dag Arne Christensen

dach@norceresearch.no

1 Institute for Social Research, Oslo, Norway

2 Norce Norwegian Research Centre AS, Bergen, Norway

3 Loyola University, Chicago, USA 
frequently fail to do so because of time constraints and lack of planning. To mobilize these voters, normative arguments in favor of voting are unnecessary; all they need is a simple nudge (Thaler and Sunstein 2009) such as can be provided by a text message. We test the Noticeable Reminder Theory through an SMS text message experiment in connection with the Norwegian local elections of 2015.

We expand on the Noticeable Reminder Theory in two important ways. First, we provide a strong test of theory robustness. Two of the previous tests have been done in the United States. We test the theory under dramatically different conditions. Among the differences is the mobilization environment. While voters in competitive U.S. elections are often inundated with canvassers, phone calls, and mailings from the parties and independent groups, there is a more limited level of direct mobilization in the Norwegian context. Another difference is the high level of turnout in Norwegian local elections (60\% in the 2015 elections), as well as a high level of knowledge and awareness of the election among the general public. ${ }^{1}$

Second, as Matland and Murray (2012) we use Zaller's (1992) receive-acceptsample theory to develop hypotheses as to which voters are likely to respond to text messages. We expect attentive voters, who are well aware of an upcoming election, to be unaffected by text message reminders. Adding one new consideration into their calculus has little impact as their calculations are already heavily weighted towards voting. On the other side, voters with little or no knowledge or interest in the election are unlikely to take note of such a small nudge. In Zaller's language they do not receive the message. These individuals require more than just a reminder to be mobilized, so we expect minimal effects there too. Rather, we hypothesize effects are strongest among voters who pay sporadic attention to politics, who are conscious of the upcoming election beforehand, but have not made explicit plans to vote. Our argument is in line with that proposed by Arceneaux and Nickerson (2009:1); "citizens whose propensity to vote is near the indifference threshold are mobilized to vote and the threshold is determined by the general interest in the election". Similarly, Enos et al. (2014) find in a study of several GOTV mobilization experiments that the treatments are least effective among low-propensity voters, but more effective among medium- to high-propensity voters.

In the Norwegian political environment, attentive voters are plentiful as average turnout for local elections is over $60 \%$. We can, however, find pockets of inattentive voters. Importantly, all eligible voters are automatically registered and need not decide to become a voter until the last minute. We find inattentive voters concentrated among those foreign nationals who newly became eligible to vote for the first time in the 2015 election (foreign nationals are eligible to vote after 3 years of legal residence in Norway). These are new voters who have not developed into habitual voters. Furthermore, many in this group are likely to have limited knowledge of the Norwegian language, and thus pay little attention to Norwegian media.

\footnotetext{
1 Turnout in the 2006 US midterm elections - the setting for the Dale and Strauss (2009) study-was $41 \%$ (of the voting eligible population). Malhotra et al. (2011) did their study in San Mateo County in California during two separate elections, a local election and a statewide primary election. The voter turnout was $4 \%$ for the local election and $9 \%$ for the statewide election.
} 
Sporadically attentive voters are voters who have a general awareness of politics but are not strongly engaged. The bulk of them are found among voters with immigrant backgrounds who have lived in Norway for a longer time ( 7 years minimum in our data) as well as among the youngest native Norwegian age cohorts who have yet to establish a regular habit of voting. Turnout in these groups is below average but they can largely follow the Norwegian media coverage and are aware of the election.

Our experiment finds text messages produce strong positive effects. Surprisingly, the messages show a positive effect among the group of foreign nationals who have become newly eligible to vote in local elections. We had expected this group to be largely inattentive. Nevertheless, the text messages produce an "intent to treat" (ITT) effect of $2.93 \%$ points (with a baseline turnout of $21.7 \%$ ). The strongest effect is among one group of sporadically attentive voters. There is an ITT effect of $4.58 \%$ points among native Norwegians below the age of 30 with a baseline turnout of $45.3 \%$. Among voters with immigrant backgrounds but who have been eligible to vote for at least one previous election, i.e. have lived in Norway for more than 7 years, we find an ITT effect of $2.73 \%$ points. Finally, SMS text messages have an ITT effect of $0.96 \%$ points among attentive voters. These effects are substantially stronger than the effects found in the United States, and stronger than the effects found in the one previous European test of text messages in Denmark (Bhatti et al. 2017).

Optimistically, this study finds both younger voters and immigrants, two groups that tend to be less plugged into the political process and vote less frequently, show the strongest effects from receiving a text message. These results indicate text messages can be an effective (and economical) tool for mobilizing voters, especially those who tend to participate less than the average Norwegian voter.

In addition to testing the effectiveness of text messages, we were interested in testing whether message timing influenced effectiveness. SMS messages were sent every day of the week prior to the election, and every hour on Election Day. Unexpectedly, the effectiveness of the messages does not vary systematically with respect to the day they are sent, while there were some differences in effectiveness based on time of day across messages sent on Election Day.

\section{Nudging People to Vote}

A well-established view in the GOTV literature is that face-to-face mobilization techniques get more voters to the polls than impersonal contact tactics such as emails and direct mail (Arceneaux and Nickerson 2009; Michelson and Nickerson 2011; Matland and Murray 2012; Green et al. 2013; Green and Gerber 2015). While proponents of mailers and text messages do not dispute this fact, they point to the vast savings in costs and labour that can be reaped by using mechanisms such as text messages and mail. While text messages may not match canvassing in terms of increasing turnout, if one calculates effectiveness as costs per extra vote, mailers and text messages can be highly effective.

The Noticeable Reminder Theory holds that a simple nudge in the form of an SMS text message can mobilize voters. In proposing the theory Dale and Strauss 
emphasize voters in the U.S. context have already shown themselves interested in voting by getting registered to vote. They do not need to be convinced to vote, they simply need to be reminded to vote. The Norwegian context differs. In Norway all voters are automatically registered to vote, there is no need to physically register, and as such the Norwegian case represents a tougher test for the theory.

Dale and Strauss (2009) in the initial paper testing text messages collected information from a sample of people who were registering to vote. These new registrants provided their mobile phone numbers and agreed to get a text message reminding them to vote. The sample was randomly split into a control group and an experimental group and individuals in the experimental group were sent a text message the day before the election reminding them to vote. Dale and Strauss found SMS reminders produced a statistically significant positive "intent-to-treat" (ITT) effect of 3.0\% points. In a second U.S. test Malhotra et al. (2011) ran two tests, during different elections, contacting a sample of voters in a single California county with cold texts (no previous contact). They find modest, but statistically significant effects, a $0.7 \%$ point increase in a local election and a $0.9 \%$ point increase for a state-wide election.

A team of Danish researchers have done the only study to evaluate text messages outside the United States (Bhatti et al. 2014, 2017). They ran three distinct text messaging campaigns during the 2013 local elections and a fourth experiment during the 2014 EU parliamentary elections. Three of the text messaging campaigns targeted young ethnic Danish voters below 30 years of age. A fourth study was conducted on a broad sample of Danish residents of all ages with an oversampling of immigrants. The Danish team tested a series of distinct messages and found no difference in effectiveness across message content. The three campaigns aimed at young voters produced a statistically insignificant $0.72 \%$ point increase in turnout, a statistically significant effect of $0.63 \%$ points with a much larger sample and finally a quite strong turnout impact of $1.8 \%$ point increase. The fourth SMS experiment resulted in an insignificant $0.33 \%$ point increase in turnout, although turnout among first generation immigrants increased by a significant $1.0 \%$ points.

In considering which voters are most likely to be affected by text messages researchers have emphasized differences in types of voters and differences in contexts. Dale and Strauss argue text messages will be most relevant for individuals with experience in voting. These individuals can make accurate estimates of the benefits versus costs of voting and have shown themselves willing to vote in the past. Their prediction is confirmed by their analyses. Looking at several types of mobilization techniques, Enos et al. (2014) find that low-propensity voters are least likely to be mobilized by a GOTV drive. Based on that, they conclude that voter mobilization may actually increase social inequalities in voting. Malhotra et al. (2011) argue the effect of text messaging is conditioned on a combination of the salience of the election and individuals' voting history. They find in the lowest salience election text messaging increases turnout only among habitual voters and in a more salient election only among casual voters. ${ }^{2}$ Voters with low levels of participation were not

\footnotetext{
${ }^{2}$ Note the turnout in the 'higher salience election' was $9 \%$ as opposed to $4 \%$ in the low salience election. Both turnout levels seem indicative of low salience elections from our perspective.
} 
mobilized. We believe variations in effectiveness are likely to depend not only on the contextual conditions, but also upon the individual voters. ${ }^{3}$ We believe Zaller's (1992) theory of opinion formation is well suited to identify voters who are likely to receive and accept simple mobilization messages such as those delivered by a text message.

Zaller's Receive-Accept-Sample (R-A-S) model of public opinion consists of four axioms. First, the reception axiom states the greater a person's cognitive engagement with an issue, the more likely he or she is to receive, i.e. cognitively process, a message concerning the issue. Simple reminders of an upcoming election are most likely to be comprehended and processed by people who have an interest in politics and the upcoming election.

The resistance axiom states people resist arguments that are inconsistent with their beliefs. For our purposes, this means people who have made a conscious decision not to vote or to simply ignore politics will be unpersuaded by an SMS reminder, especially since the messages do not contain any strong normative arguments. The accessibility axiom says that recently received or used considerations are more prominent in our cognitive structure and are more easily recalled when making a decision. The relevant considerations in our study are thoughts about voting in the election. Finally, the fourth axiom deals with how people make decisions. It states people average across considerations that are immediately salient or accessible (Zaller 1992:49). A text message urging people to vote, especially if sent just before deciding whether to vote, makes the pro-voting considerations more salient and impactful.

The R-A-S model leads us to expect attentive voters who follow the election campaign will notice and cognitively process the voter mobilization messages, but these voters are unlikely to be much affected. They will vote anyway. At the other end of the attentiveness-spectrum inattentive voters who perhaps are not even aware of the upcoming election may not take note of a simple text message with no additional information. They may read the text message but do not receive the message in terms of processing the information. They see the message as irrelevant to them. To mobilize this group a simple nudge is insufficient; they would need more information to convince them of an election's relevance to them.

In between these two poles, we find the sporadically attentive voters. They are probably aware of the upcoming election, though they do not follow the campaign in detail. Furthermore, they are generally predisposed to vote, perhaps as a response to civic duty but voting is an action with small benefits and small costs (Aldrich 1993).

As relatively small value is generated by voting and the costs of not voting are modest they may be hindered from doing so for practical reasons such as running out of time or simply forgetting. For this group a noticeable reminder can be an effective mobilization tool. We expect reminders to be more effective as they are given closer to Election Day. We test these hypotheses through a GOTV experiment with SMS text messages in connection with the Norwegian local elections of 2015.

\footnotetext{
3 See our pre-analysis for a discussion of data, experimental design and possible heterogeneous effects (https://egap.org/registration/1312).
} 


\section{Experimental Setting and Data}

Previous text message mobilization experiments have mainly been conducted in the US. Our setting differs in several notable ways. First, the voter mobilization environment is very different. The Norwegian political system is party-centered and there is limited personal campaigning by individual candidates. There is some door-to-door canvassing, but mailing, phone calls, and text messages are not common forms of communication between parties/candidates and voters. A direct contact with voters via text is unusual and therefore is likely to be noticed.

Second, while Norwegian local elections are often referred to as "second order elections" (Mjelde et al. 2015) and they receive less attention and interest than parliamentary elections, turnout in these elections is still high. In the 2015 local election, $60.2 \%$ of all eligible voters took part. This was an unusually low level of turnout by Norwegian standards, ${ }^{4}$ but is vastly higher than the elections where U.S. studies of mobilization techniques are fielded. However, turnout in the Norwegian 2015 local election was 12\% points lower than in the Danish 2013 local elected where four SMS Text messaging experiments was fielded. Still, general knowledge and awareness of the election is widespread in Norway. The campaign is covered widely in every news media and media consumption is comparatively high.

Note also that Norwegians are asked to go to the polls and vote only twice in a 4 year time period. Americans, depending on one's state of residence, may vote more than 20 times in a 4 year period. Elections in Norway are rarer, and no election is considered obscure or only of minor interest. In short, in the Norwegian context most voters are attentive. This means, in the context of mobilization studies, that Norwegian local elections are best described as high-salience, high-involvement elections. A lot of voters are attentive and inclined to vote. Involvement is especially pronounced among natives above the age of 30, who turned out to vote at a rate of $73 \%$ in the 2015 elections. We define these voters as our "attentive public".

An inattentive audience is harder to come by. ${ }^{5}$ It is almost impossible for those who understand the Norwegian language and pay at least sporadic attention to media coverage to be unaware of an upcoming election. One group may, however, fall into the inattentive category: newly arrived immigrants with voting rights. After 3 years of legal residence immigrants to Norway automatically receive voting rights in local elections. ${ }^{6}$ We use this rule to define our inattentive voters as immigrants who were first eligible to vote in the 2015 local elections. These immigrants established residency between 2009 and 2011. Voter turnout in this group is low: $21.6 \%$ in 2015. We expect this group to have limited, but varying, knowledge of the Norwegian language. For most immigrants, Norwegian is a completely new and foreign language.

\footnotetext{
4 This was the second-lowest level of turnout in Norwegian local elections since World War II. The record-low was set in the 2003 elections $(59.0 \%)$.

5 The norm in the United States is to use an individual's voting record in previous elections to identify them as a habitual, episodic, or registered non-voters. Voting records at the individual level are unavailable in Norway so we are forced to use demographics to identify groups of voters based on official statistics and election surveys rather than individual voters based on their individual voting record.

6 Norwegian citizenship is required to vote in national parliamentary elections.
} 
Table 1 Voter turnout, political interest, frequency of political conversations and party identification across four groups of voters [\%]

\begin{tabular}{|c|c|c|c|c|}
\hline & \multirow{2}{*}{$\begin{array}{l}\text { Inattentive audience } \\
\text { Immigrant first time voters }^{\mathrm{a}}\end{array}$} & \multicolumn{2}{|c|}{$\begin{array}{l}\text { Sporadically attentive } \\
\text { audience }\end{array}$} & \multirow{2}{*}{$\begin{array}{l}\text { Attentive audience } \\
\text { Natives aged } 30 \text { or more }\end{array}$} \\
\hline & & $\begin{array}{l}\text { Other } \\
\text { immigrant } \\
\text { voters }\end{array}$ & $\begin{array}{l}\text { Natives } \\
\text { below age } \\
30\end{array}$ & \\
\hline Voter turnout & 22 & 40 & 45 & 73 \\
\hline $\begin{array}{l}\text { Very or somewhat } \\
\text { interested in local } \\
\text { politics }\end{array}$ & 40 & 44 & 33 & 66 \\
\hline $\begin{array}{l}\text { Have weekly con- } \\
\text { versations about } \\
\text { the election }\end{array}$ & 24 & 38 & 36 & 51 \\
\hline Party identification & 56 & 71 & 67 & 75 \\
\hline Survey data N & 1143 & 2392 & 638 & 1394 \\
\hline
\end{tabular}

Voter turnout is measured based on electoral roll data in the 27 Norwegian municipalities where our experiment was carried out. The survey results come from an election survey carried out by Statistics Norway (https://www.ssb.no/en/valg/statistikker/vundkomm)

${ }^{\text {a }}$ Three years of continuous legal residence is required for a foreign national to receive voting rights. Local elections are held every 4 years. First time voters are therefore people with 3-7 years of residence. This group is precisely identified in the voter turnout data. In the Election survey among voters with an immigrant background we have to use the category "3-9 years of residence"

Consumption of Norwegian language media is therefore likely to be lower for this audience than for the rest of the population. This group may also lack the contextual information necessary to make sense of an SMS voter mobilization message. Immigrants from Sweden and Denmark on the other hand generally understand Norwegian, since the three Scandinavian languages are quite similar. Finns are required to learn Swedish in school and all four countries have cultures with many similarities. Citizens from other Nordic countries have voting rights in local elections if they are registered resident in Norway no later than 30 June in the year of the election. We have therefore chosen to exclude immigrants from the Nordic countries from our samples of immigrants participating in their first election (inattentive voters), but they are included in our samples of attentive voters. Finally, the remaining groups of voters are young native Norwegians below the age of 30 and immigrants who have lived in Norway longer and had voting rights in at least one previous election. Turnout in these groups is below native Norwegians 30 and over in age but comfortably above recent immigrants (see Table 1). They are moderately interested in politics and pay sporadic attention to the election campaign.

Table 1 provides evidence of real differences in attentiveness to politics between these three groups. The turnout-rates are a strong behavioural indicator. In addition, the results from an election survey carried out in 2015 regarding political interest, conversations about the election and party identification indicate clear differences in attitudes between these groups of voters. Across these items, the inattentive audience has the lowest levels of political involvement, whereas the attentive audience 
is at the opposite end of the scale. With the possible exception of the political interest question (in which young natives display low levels of interest), the sporadically attentive audience are in the middle on all indicators.

\section{Study Population and Experimental Design}

In designing the experiment, we had access to the electoral rolls for approximately 1.7 million Norwegian voters living in the 27 municipalities $^{7}$ (out of a total of 428 municipalities) that had adopted electronic registration of turnout. Because practically all of Norway's larger towns and cities have electronic registration of turnout, our dataset includes $42 \%$ of Norway's eligible voters. To pull our samples we needed additional background information to separate immigrants from the native Norwegian population. The National Population Register [Folkeregisteret] provided information with respect to birthdate, sex, country of origin, and citizenship. For those who immigrated to Norway we also have the date of entry to Norway. The latter information was used to identify immigrants newly eligible to vote.

The datafile includes 279,230 voters with immigrant backgrounds, of whom 69,086 are eligible to vote in Norway for the first time. It also contains 1,363,083 individuals who are Norwegians without an immigrant background; 328,167 of those are below the age of 30 .

We contracted with an IT-company to provide cell phone numbers tied to the individuals in our voting registry. They were able to match phone numbers to $73 \%$ of the immigrant voters; thus reducing our sample to 202,496 individuals. Cell phone coverage in the Norwegian population was slightly higher: $76 \%$; thereby limiting the sample to $1,042,264$.

Another mobilization experiment that targeted immigrants ${ }^{8}$ involved 13,733 individuals in our sample, which we excluded (reducing the immigrant sample to $188,763)$.

Finally, when pulling the samples for the households with more than one voter, we aimed at pulling only one person per household, to avoid sending multiple messages to the same household. We did not have a specific household identifier in our data, so we identified households by address. In some cases, addresses were detailed, i.e. identifying individual apartments within larger apartment-buildings. In other cases, addresses were not very specific, in that every person in an apartment building had the same address. Our measure of household is therefore less than ideal. The practical consequence of that is that we end up discarding a number of voters from our data file that we would have included if we had a better household indicator. This is not a problem for our analytical purposes, as long as the samples are in the hundreds of thousands.

\footnotetext{
7 The 27 municipalities are (ordered by population size, from large to small): Oslo, Bergen, Trondheim, Stavanger, Bærum, Fredrikstad, Drammen, Sandnes, Sarpsborg, Asker, Skien, Skedsmo, Bodø, Sandefjord, Larvik, Tønsberg, Karmøy, Porsgrunn, Haugesund, Ålesund, Mandal, Vefsn, Hammerfest, Re, Tynset, Radøy and Bremanger.

8 Bergh et al (2016).
} 
Table 2 SMS text campaign: control and treatment groups

\begin{tabular}{lll}
\hline & Treatment & Control \\
\hline First generation immigrants & 48,005 & 77,148 \\
Native norwegians & 75,559 & 379,634 \\
Total & 123,564 & 456,782 \\
\hline
\end{tabular}

We proceeded to sample individuals 9 in the following manner: For "households" that included 1 to 5 individual voters ${ }^{10}$, we sampled one person. This includes $92 \%$ of our sample. For larger households we sampled one additional name if the household had between 6 and 17 individuals. We then sampled one additional person for every 12 additional individuals in the household.

This procedure left us with what we considered to be too few individuals in the category of voters with immigrant backgrounds who were eligible to vote for the first time (about 12,000). We therefore dropped that procedure for this part of the sample. The category of "immigrant first time voters" includes everyone that had a registered phone and that were not part of any other experiment. The practical consequence of this is that some people in the control group will be in a household that receives and SMS. This could potentially raise turnout in the control group, thus reducing effect sizes. There is a chance, in other words, that we may underestimate effect sizes in this group.

All in all, we ended up with 125,388 voters with immigrant backgrounds, of whom 41,400 were eligible to vote for the first time. The native Norwegian sample was reduced to 455,193 voters.

From these samples we then sampled individuals to receive treatment; those not getting treatment constitutes the control group. Table 2 displays the composition of the control and treatment groups.

Text messages were sent in the last week up to and including Election Day (from Monday September 7 to Monday September 14). The number of text messages sent per day ranged from 8500 messages to 16,500 . These went out at $7 \mathrm{pm}$ each night leading up to the election, summing to a total of 73,146 messages. The second round of messages was sent on Election Day, starting at 8 am and then every hour until 6 pm: 58,169 messages were sent on Election Day. Each subject only received one text message.

The text messages were sent by a polling agency with the technical equipment to send large numbers of text messages simultaneously. Furthermore, the firm kept track of which messages were delivered. That enables us to calculate precise treatment effects. The cost of the text messages used in this study was 0.70 kroner $(8.5$ US cents) per message, so this is clearly an inexpensive way of contacting large groups of voters.

\footnotetext{
9 We sampled individuals to be included in either the treatment or the control groups. Sampling to treatment was then done from this sample of individuals.

10 Children below the age of 18 are not included in the file, since they do not have voting rights.
} 
To be able to compare our results with previous experiments we use similarly phrased text messages. The text messages included a reminder of the upcoming election with a short civic duty appeal. SMS\#1 was used for messages sent the week before the election. SMS\#2 was used for messages sent the day of the election.

SMS\#1 Hi! This is a friendly reminder concerning the local election on September 14. Democracy needs your voice/vote ${ }^{11}$, so remember to participate in the election! Regards valg.no.

SMS\#2 Hi! Have you voted? If not, you can still make it. Polling stations are open from XX to YY today. Participate in the election! Regards valg.no.

Message content was developed in agreement with the Ministry of Local Government and Modernization (KMD). KMD has overall responsibility for all elections in Norway and we used their election webpage address valg. no (election. no) as the sender of the messages (Bergh et al. 2016). The receivers of the SMS had not given prior consent to receiving these messages from the Ministry which strengthens the external validity of the experiment (Michelson and Nickerson 2011: 235). We are studying the effect of "cold" text messaging (messages without prior consent) like those used by Malhotra et al. (2011) as opposed to the "warm" messages (messages with prior consent) used in the original Dale and Strauss (2009) study. Therefore, our strong results cannot be explained as unique to recipients who previously agreed to receive texts.

\section{Results}

We have two aims. First, to test the robustness of the U.S. text messaging ${ }^{12}$ results when applied in a European context. Did text messaging work on Norwegian voters? Second, to look across groups to see where the messages are most effective. We predict differences in the effectiveness of the mobilization messages, based on voter attentiveness.

The intent-to-treat effect (ITT) is a conservative standard for analyzing results from clinical trials, it evaluates subjects as they were originally randomized regardless of whether they received/completed the treatment or not (Gerber and Green 2012). ITT analysis maintains the benefits of randomization and provides an accurate measure of how effective a treatment is given realistic conditions where coverage is less than complete.

Table 3 presents our results with the first column showing the control group turnout and the second column showing the ITT effect (see on line Appendix A for the bivariate regressions). We also did a robust check in which we used inverse

\footnotetext{
11 We used the Norwegian word "stemme", which means both "voice" and "vote".

12 The data and the code used to produce results are at https://dataverse.harvard.edu/dataset.xhtml?persi stentId=doi:10.7910/DVN/IEDGNU
} 
Table 3 Experimental results: base turnout and change in turnout

\begin{tabular}{|c|c|c|c|c|c|c|c|c|}
\hline & \multirow[t]{2}{*}{$\begin{array}{l}\text { Control } \\
\text { group } \\
\text { turnout }\end{array}$} & \multicolumn{2}{|c|}{$\begin{array}{l}\text { Intention to } \\
\text { treat (ITT) }\end{array}$} & \multicolumn{2}{|c|}{$\begin{array}{l}\text { ITT with } \\
\text { control vari- } \\
\text { ables }\end{array}$} & \multicolumn{2}{|c|}{$\begin{array}{l}\text { Complier } \\
\text { average } \\
\text { causal effect } \\
\text { (CACE) }\end{array}$} & \multirow[t]{2}{*}{$\mathrm{N}$} \\
\hline & & Effect & S.E. & Effect & S.E. & Effect & S.E. & \\
\hline \multicolumn{9}{|l|}{ Inattentive audience } \\
\hline First-time voters (foreign nationals) & 21.68 & 2.93 & .50 & 4.27 & .48 & 4.83 & .82 & 41,400 \\
\hline \multicolumn{9}{|l|}{ Sporadically attentive audience } \\
\hline Other first-generation immigrants & 41.31 & 2.73 & .34 & 2.16 & .33 & 4.36 & .55 & 83,988 \\
\hline Natives, below age 30 & 45.33 & 4.58 & .48 & 3.31 & .47 & 6.16 & .64 & 66,086 \\
\hline \multicolumn{9}{|l|}{ Attentive audience } \\
\hline Natives, aged 30 or more & 72.66 & .96 & .20 & .38 & .19 & 1.36 & .27 & 389,107 \\
\hline
\end{tabular}

The following social background control variables are included: sex, age, and married. In addition, for immigrants we included "Western" (immigrants from Europe, North America, and Oceania), and years in Norway. For all four groups a dummy for living in Oslo is included

probability weights (IPW) to test if the probability of treatment varied by household size (see on line Appendix B). Finally, we ran regression models with control variables (see on line Appendix c). Including control variables should not change the treatment effects notably compared to the model without controls because randomization should guarantee the treatment is uncorrelated with any relevant control variable (Angrist and Pitschke 2008).

While ITT is a conservative measure, the Complier Average Causal Effect (CACE), column three, is relatively liberal as it considers only on those who received the treatment. CACE effects are calculated using a two-stage least squares regression of vote on actual contact using selection into the experimental group as an instrumental variable (Gerber and Green 2012). Since there are some differences in sampling strategies between groups, we opt for not presenting combined effects across groups.

Looking at the effects, we begin with immigrants who are first-time voters. $21.7 \%$ of those in the control group voted, while those in the experimental group voted at a rate of $24.6 \%$ suggesting that being scheduled to receive the SMS increased turnout by $2.9 \%$ points (S.E. $=.50)$. Adding controls reduces the effect somewhat for three of our four groups. For foreign nationals who are first time voters adding controls increases the ITT to $4.27 \%$ points and the CACE was a strong $4.8 \%$ points.

Immigrants who have lived in Norway for 7 years or more voted at a rate $(41.3 \%)$ about twice that of first-time voters with an almost identical treatment effect, 2.7\% points. This effect drops slightly with the inclusion of the control variables, to $2.2 \%$ points. The CACE effect in this group is also strong, $4.4 \%$ points. The general pattern seems to be that once immigrants are contacted text messages are an effective mobilization tool.

Native Norwegians below the age of 30, our second group in the category of "sporadically attentive audience", has a control group turnout of $45.3 \%$. Text messaging has a remarkably strong effect in this group: $4.6 \%$ points which decreases to 
$3.3 \%$ points when controls are added. The CACE effect is estimated as $6.2 \%$ points. Young Norwegians are clearly mobilized by text messages. On the other hand, native Norwegians 30 and above, our attentive public, show a positive but only modest effect. The already high turnout in this group rises with a statistically significant $.96 \%$ points in the treatment group. Controlling for the contact rate, we find a modest CACE effect of about $1.4 \%$ points.

The distinction between the ITT and the CACE effect is driven by the contact rate. For each text message we sent we got either a confirmation the message was delivered or a message noting a failure to deliver. While there were failures in all four groups there were considerable differences in contact rate. While $88.3 \%$ of native Norwegians assigned to receive a text message were successfully contacted, the contact rate was substantially lower for immigrants: $70.8 \%$. In addition, a number of voters made use of early voting, and therefore had voted before they received their text message. We have registered the precise time people voted and can therefore determine the share of voters that voted prior to receiving our text message. $19.5 \%$ of the native Norwegian sample and $12 \%$ of the immigrant population had already voted when they received their message. ${ }^{13}$ Thus, the contact rate for firsttime voting immigrants is calculated to be $60.6 \%$, other immigrants $64.6 \%$, and the contact rate for the two Norwegians samples are $74.3 \%$ (below the age of 30), and $70.4 \%$ (older than 30).

Overall, we find text messaging is effective in Norway. There is a statistically significant increase in turnout across all groups. The effectiveness does vary across groups. Overall, the results support our predictions with respect to the effectiveness of text messaging with sporadically attentive and attentive audiences. The effect of text messaging in our inattentive group of voters, however, is higher than expected. Clearly, text messaging also works as a mobilization tool among immigrants who are newly eligible to vote.

Of course, having to define our inattentive audience in terms of all members of a group rather than based on individual information makes it more difficult to identify the truly inattentive. The mandatory "introduction program" that refugees and asylum seekers go through, which includes teaching of the Norwegian language, could enable quite a few to follow Norwegian election campaigns. Within this group there likely are individuals who are more attentive to politics than we originally expected; or at least they are attentive enough to receive, accept and act upon a voter mobilization text message. Furthermore, even if these immigrants are relatively new there are members of their community with substantially greater experience in Norway who can provide essential cues as to how to interpret politics in Norway and how

\footnotetext{
13 While some messages were delivered after voters had voted we still elect to use the whole sample in our calculations of ITT and we do not adjust the CACE sample (if the message was successfully delivered the voter is a complier whether they had voted early or not). This is because adjusting the treatment sample by dropping these cases while not adjusting the control sample for those who voted prior to sending out messages will bias our estimate of the treatment effect. We could drop all voters from both the experimental and control samples who voted prior to us sending out text messages but this should result in largely the same estimates in terms of treatment effects.
} 
to vote. ${ }^{14}$ We find some indication this may be going on in the control variables included in Appendix B which show that immigrants living in the capital of Oslo are more likely to vote than their equivalent compatriots in other areas of the country (Bergh and Bjørklund 2010).

\section{Does Timing Matter?}

A final issue is whether the effectiveness of the text messages is influenced by the time when messages were sent. In the literature, the jury is still out concerning the ideal time to deliver GOTV-appeals. Most of the literature supports the idea that the closer to the election the more effective messages are. Nickerson (2006), looking at the effectiveness of GOTV phone calls, argues calls the last week are effective, but calls made earlier than 1 week before do not have an impact. Murray and Matland (2014) find that GOTV postcards with voting records work 1 week prior or less to Election Day, but earlier mailers have limited impact.

The one study arguing early contact can be just as effective is Panagopoulos (2011). He argues there is a primacy effect which results in the early delivery of GOTV-appeals having a memory advantage, while the recency hypothesis argues that delivery close to the election put such appeals in the forefront of recipients' short-term memory when they have to make the decision to vote (Matland and Murray 2012). Panagopoulos found appeals to high-propensity voters delivered 4 weeks prior to Election Day were more effective than appeals delivered 2 weeks prior. Thus, it is an open question whether "messages delivered early mobilize as effectively as appeals received closer to Election Day" (Panagopoulos 2011: 80).

Given the very limited information that can be included in a text message the initial SMS studies using messages argued their effectiveness was based on their value as a reminder to plan to vote. The effect was seen to be transitory so both U.S. trials only sent messages the final weekend before the election. The R-A-S model also expects recency to matter, the model emphasizes that when sampling considerations and deciding whether to vote, more recent considerations are more salient and more likely to be sampled (Matland and Murray 2012).

In our experiment, text messages were sent out daily in 1 week leading up to Election Day. This is a shorter period of time than that used by i.e. Murray and Matland (2014), so it is possible that our timeframe is too brief to uncover major differences in effects.

For our analysis we use OLS regressions. The regressions are used to calculate the marginal change in turnout among members of the experimental groups (i.e. those who received a text message). The change in vote probability by day is presented graphically in Fig. 1a, b. The figures show the variation in the effectiveness

\footnotetext{
14 Several of the immigrant communities, especially in the larger cities, have built strong ties to specific parties, primarily with Labour, and political outreach to the community does occur. Furthermore, local elections in Norway allow for personal voting and several immigrant politicians have been elected to local councils based on personal votes from their community.
} 


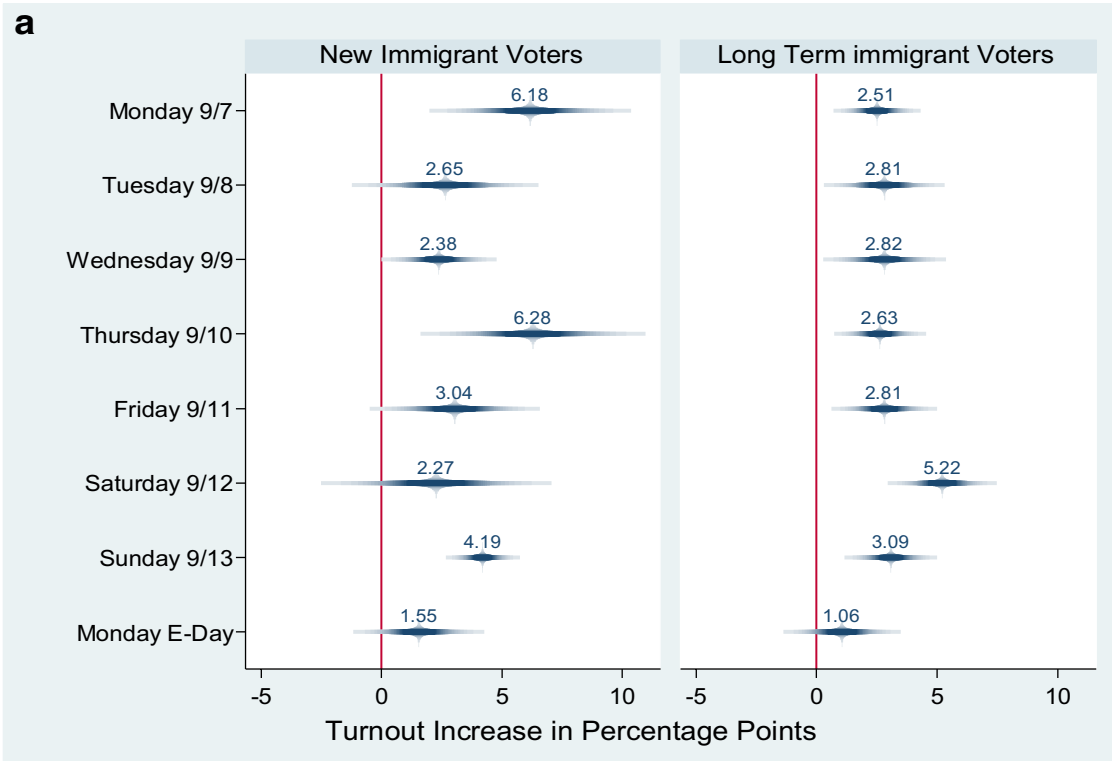

b

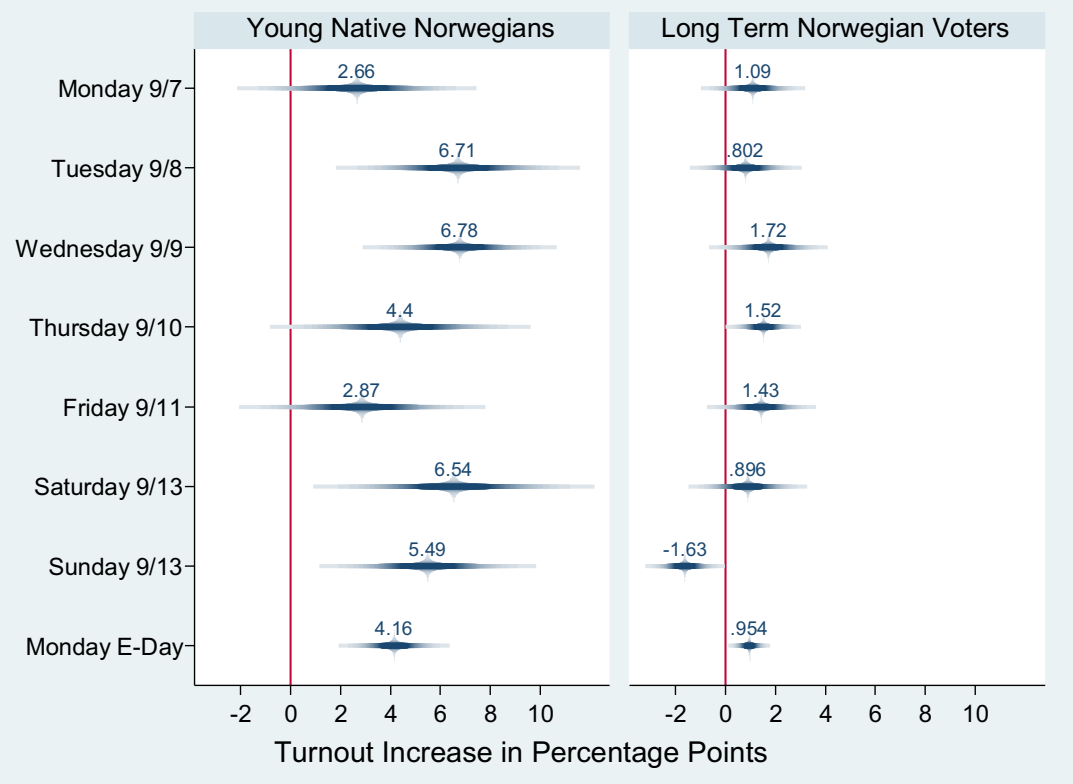

Fig. 1 a Date of delivery effects: immigrant sample. b Date of delivery effects: native norwegian sample

of the text messages from 8 days prior (Monday: 9/7/2015) through Election Day (9/14/2015), first for immigrants and then for native Norwegians. 
Figure 1a shows the point estimates and 95\% confidence intervals for immigrants who are eligible to vote for the first time and longer-term immigrants. For both groups the point estimates suggest text messages have a positive effect on turnout every day. For first time eligible immigrants effects vary across time; some are significant, some are not. The impact is more consistent among long term immigrants. There is no clear chronological pattern for either group as the effects do not get stronger (or weaker) over the space of the week. Furthermore, time effects are inconsistent across groups. So, while Saturday, 2 days before the election shows the strongest effect for long term immigrants, Saturday shows the second weakest effect for first time immigrant voters. Simultaneously Monday a week before the election has the next strongest effect for first time immigrant voters, while it is the second weakest days for long term immigrants. These patterns strengthen the suspicion this is probably just random noise.

When evaluating the native Norwegian results in Fig. $1 \mathrm{~b}$ we see there is a significant difference in effectiveness across age groups. For Norwegians below 30 text messages have impact regardless of when they are delivered. Every single day shows an effect greater than a $2.6 \%$ point increase in turnout and 6 of the 8 days show more than a $4 \%$ point bump. These are very strong effects, but as with the immigrant samples there is no consistent chronological pattern. Recall for native Norwegians 30 and over the overall effect reported in our regression was small (.96) but positive. Figure $2 \mathrm{~b}$ reflects this, showing a very stable pattern with little variance in effectiveness, on no day was the increase in turnout as much as $2 \%$ points. Except for Sunday, every day was positive. While no individual days are significantly different from zero, collectively there is a positive impact.

Turning to our by-the-hour experiments on Election Day the results are displayed in Fig. 2a, b. The results among immigrant voters shows a couple of patterns. For newly enfranchised immigrants, the effects during the day (between 10:00 and 16:00) show fairly substantial positive results. The earliest messages and the latest messages have negative and insignificant effects. Text messages sent at 12:00 and 16:00 have positive effects. There is similar day of the election effects for immigrants who have lived in Norway for more than 7 years, the text messages sent at 8:00 or at 18:00, i.e. early or late, shows smallest effects with the strongest effects being in the middle of the day.

One very clear outcome is the significant difference in effects between the sporadically attentive and the attentive voters. Among Norwegian natives 30 and above (i.e. attentive voters) we sent out messages at ten different times. Nine of the 10 times showed no significant effect while one had a significant positive effect (4 pm). Combined this supports the argument that Election Day text messages have little impact on attentive voters, although the combined effect of all the messages is a small significant positive effect.

For less attentive Norwegian natives, emblematic of the younger voters, there are consistent and stronger effect. The very earliest messages (8:00) and very late messages (17:00 and 18:00) did not have a significant impact on turnout. The messages at 9:00, 12:00, 13:00, 14:00, 15:00, and 16:00 all had significant impacts. In other words, 5 of the 10 separate trials on Election Day. There is some random variation in Fig. 2b as well, but the general conclusion seems to be voter mobilization 
a

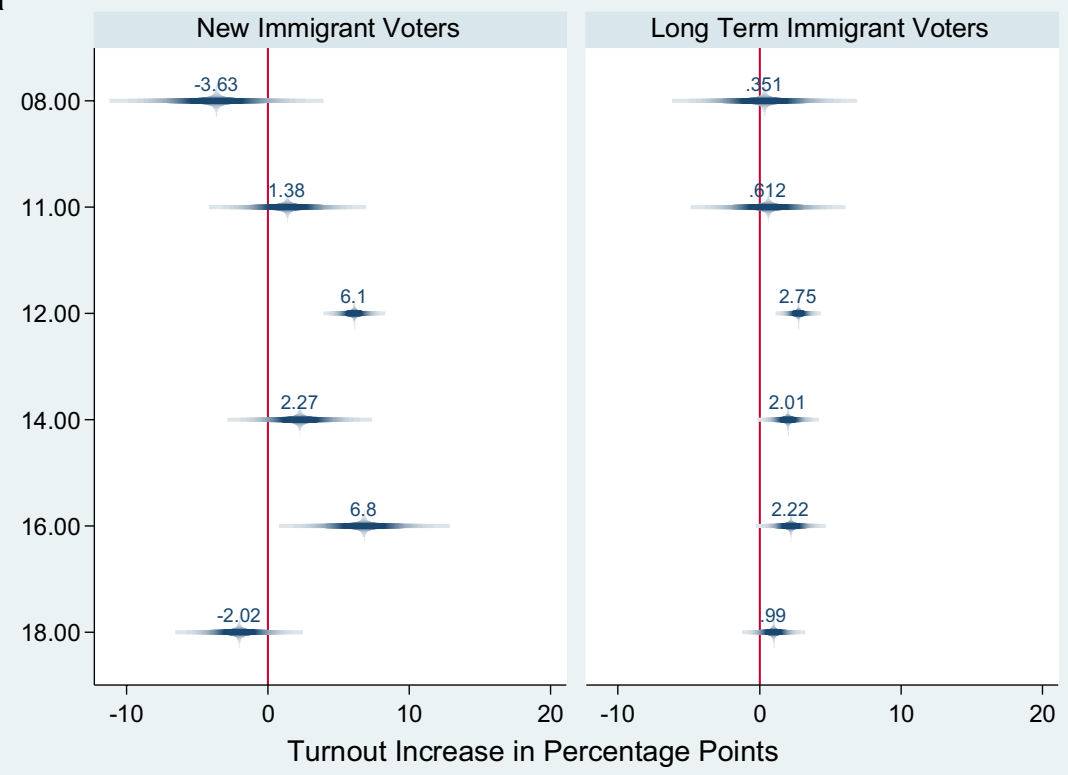

b

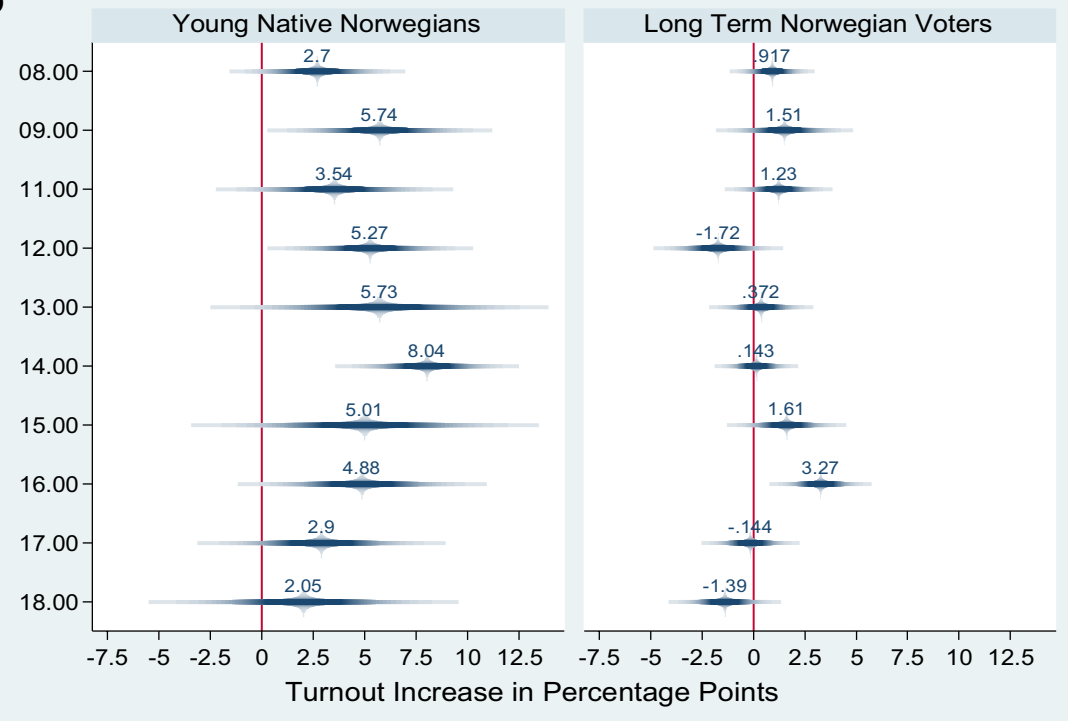

Fig. 2 a Hour of delivery effects: immigrant sample. b Hour of delivery effects: norwegian sample

text messages should be sent during the middle of the day on Election Day. Interestingly for three of the four samples the strongest effect is the 16:00 round of text messages. Among the four separate samples this time produced percentage point 
increases of $6.8 \%, 2.2 \%, 4.9 \%$, and $3.3 \%$, truly strong effects. If we were to predict a time that would work well as a reminder it would be 16:00. Most Norwegians finish work at 15:45 or 16:00 so the text message shows up just as they are leaving work and on their way home. A noticeable reminder just as they head home enables them to stop and vote before they get home and appears to work extremely well.

\section{Discussion}

The existing literature argues impersonal mobilization tactics are ineffective or produce only small positive results (Green and Gerber 2015). The data and analyses we present challenges that suggestion. Especially when the cost of contact is calculated text messaging is effective, at least in Norway. While the results from the one U.S. study using cold texts (Malhotra et al. 2011) found effects in a low turnout election just below $1 \%$ point. Our results find text messages can have considerably stronger effects. Messages sent a full week before the election were just as effective as those sent the day before the election. The effects were powerful, CACE estimates show 4-6\% point increases in turnout for three of our four groups.

Our results suggest text messages may be more effective in a European context than in the US. A key reason is the difference in mobilization environments. While U.S. voters are commonly exposed to direct campaign communications through mail, telephone, and sometimes text messages, Norwegian voters are far less exposed to these contacts. When such activities do occur they are more likely to be noticed and acted upon.

We suspect another reason for the effectiveness of text messages in Norway is this communication channel is fairly personal, at least when compared to marketing phone calls or e-mails. Our cellphones have become an intimate part of our lives. Yet, receiving text messages from institutions or commercial companies is still uncommon, therefore public service announcements may get noticed. Garcia Bedolla and Michelson (2012):33 argue that if "messages from strangers become more common, we assume that their impact will decrease because they will seem less like a social contact". Ironically this suggests our text messages worked partially because they are rare. If research leads to the widespread adoption of text messaging it is entirely plausible their impact will drop as their use increases.

We based our theoretical predictions on applying Zaller's R-A-S model to a mobilization campaign. Parts of our results fit the Zaller model quite well. As predicted attentive voters are only modestly impacted by a nudge in the form of a text message. There is a small positive effect of mobilization messages for this group. Further, as predicted, the strongest impacts were among the sporadically attentive. Native Norwegian voters below the age of 30 responded strongly to the mobilization message. We suspect many members of this group, whose turnout is below average, have the intention to vote, but fail to do so for practical or convenience reasons. Furthermore, as part of a younger generation with distinct communication patterns, 
text messages may actually have a greater possibility of connecting with these voters than traditional canvassing and mailings.

We also find a strong effect among long term immigrants who are better integrated into Norwegian society than their newly arrived compatriots. A nudge in the form of a text message is especially effective for this group. Note while this pattern fits the R-A-S model it is inconsistent with the description of the noticeable reminder theory which strongly suggested the largest effect would be among those "who have had experience deciding to vote in previous elections" (Dale and Strauss 2009: 7).

Not all the results, however, are consistent with the R-A-S model. In the group of inattentive voters (foreign nationals with no previous voting history in Norway), who we had predicted would not be swayed by text messages, we find a noticeable effect. As expected the effect among this group is smaller than among the sporadically interested, but it is still present.

A couple reasons come to mind for why this effect is stronger than expected. First, the text message may provide more than a simple nudge. A text message from the official organizers of the election (the Local Government and Modernization Ministry) confirms a citizen's eligibility to vote. In post-election polling done by Statistics Norway (2016) one in eight immigrants who had the right to vote said they did not do so because they believed they were not eligible to vote. Even if all voters are automatically registered to vote, $10 \%$ of newly arrived are not aware of their voting rights. This effect is greatest among the newly eligible. For these recipients the text messages provided valuable information about their voting eligibility not just a voting nudge. In addition, the designation of newly eligible immigrants as broadly inattentive is probably correct, they have the lowest turnout rate and the lowest level of political interest of our groups. Yet even within this group there will be individuals with considerable interest in politics who can be nudged to the polls via a simple text message.

The second way the results seem inconsistent with the R-A-S model is there is no decay in effect as time before the election gets larger. We had suggested that one of the reasons a noticeable reminder would work is because it would be salient and on the top of the process of recalling considerations when received just before voting. This is less true the farther from the election one gets. Yet there appears to be no diminution in the effect as the time until Election Day increases. ${ }^{15}$ This could be because the variations in timing in our experiment are limited; all messages are sent out within a week. We cannot discount the possibility that text messages sent out over a larger period of time would have produced differences in effects based on timing.

\footnotetext{
15 We tested one possible explanation for this which is a text message received a full week before the election might inspire voters to vote early and not wait to Election Day to vote. Perhaps in this manner there would be a primacy effect. In fact text message recipients were slightly more likely to use early voting but the effect was not significant and nowhere near large enough to explain the total effect of early text messages.
} 
In comparing our results with the one other test of text messages in Europe, the Danish experiments (Bhatti et al. 2014, 2017), we find text messages are more effective in Norway than Denmark. Until further experiments are run we can only speculate about the causes of these differences, among the causes, this difference may simply be caused by random noise. While similar, the two Scandinavian studies do not have identical designs; there are differences in the samples, in the messages, and the election context. Voter turnout in the Danish local election of 2013, used for three of the experiments, was 12 points higher than in the Norwegian local election of 2015. There are, in other words, more potential voters to mobilize in the Norwegian case. There are also noticeable differences in the samples. The Danish studies had data initially on $99 \%$ of voters, we had $42 \%$ of voters. The difference is that in the Danish study they had the resources to manually enter all election data for those localities, primarily small municipalities that did not electronically register turnout. In the Norwegian case we did not have the resources for this expansion.

An additional distinction is there was a noticeable difference in identifying cell phone numbers for the voters pulled. While we received cell phone numbers for $76 \%$ of our voter sample, the Danish researchers received cell phone numbers for between 34 and $49 \%$ of their experimental samples. If the differences in cell phone coverage are systematically related to issues such as length of time the individuals have had their phones, the Norwegian lists may be more likely to include voters who have owned their phones for a shorter period of time. Shorter time with a new phone number may also be indicative of being younger and this could easily be associated with being sporadically attentive, precisely the people we find most sensitive to our messages. If the Danish list is dominated by individuals who have had their cell phones for a long time those listings are likely to lean heavily in the direction of individuals who are in stable life situations who are more likely to be attentive and participating, diminishing the overall impact of the text message.

Finally, the populations were pulled differently. If a household had more than one cell phone listing in the Danish case these households were not included in their study, only households with one cellphone were included. In the Norwegian case when there was more than one cellphone in a household (address) we randomly chose one individual per household to be included in the study. Both methods are defensible, but they do mean the samples are not the same which may explain the differences in results. In sum, there are a variety of differences that may help to explain the divergence in results between the Danish and Norwegian studies. The most obvious solution is to simply urge further studies to see if the strong effects found in Norway hold up in other European countries and to repeat attempts to produce significant results in Norway. In doing so it may be possible to incorporate into the experimental design ways to control for the possible differences listed above.

\section{Conclusion}

We believe this study supports several important conclusions. First, text messages are an effective tool for mobilizing voters in Norwegian local elections. Given the size of the effects and the modest costs associated with text messaging, 
text messaging holds considerable promise as a tool for voter mobilization. Just as important is the clear indication that European results need not mimic U.S. results. One cannot assume that U.S. findings can be safely transferred to Europe. Our work finds very different results. While text messages had weak effects in the United States they were quite strong in Norway. ${ }^{16}$ Further work is needed in the European arena to see what effects transfer from the United States to Europe.

Not only are there differences in the impact of these tools across the Atlantic, there is also a significantly different distributional pattern than found in U.S. studies. The US GOTV literature consistently finds mobilization effects are strongest among habitual voters (Enos et al. 2014). GOTV campaigns tend to increase the age and class skew of the voting pool in the United States. For Norway we find precisely the opposite effect. It is among voters with lower turnout rates (immigrants and the youngest native Norwegians) that text messages are most effective. This may be our most important finding. Whereas U.S. GOTV tools are fairly ineffective at incorporating new voters, our findings from Norway present a very different pattern. An outcome portending serious benefits. Bringing in younger voters puts them more quickly onto the path of becoming long term habitual voters and can lead to significant downstream benefits. Bringing immigrants in provides extremely important benefits in terms of increased integration into society leading to reduced alienation (Bergh et al. 2016). Improved integration of immigrant communities has to be one of the top priorities in Europe and voter mobilization campaigns may prove to be a useful tool to achieve this.

We also believe our results suggest important results for the research community interested in mobilization. Text messaging has not been studied sufficiently. While the initial effects appeared small in the United States, no one has tried cold texts in an election where turnout was above $9 \%$. Furthermore, the finding that text messages were especially useful among youth voters suggests testing this tool should be tested among college students. Our results suggest further tests both on the North American side and on the European side of the Atlantic would be useful.

Open Access This article is distributed under the terms of the Creative Commons Attribution 4.0 International License (http://creativecommons.org/licenses/by/4.0/), which permits unrestricted use, distribution, and reproduction in any medium, provided you give appropriate credit to the original author(s) and the source, provide a link to the Creative Commons license, and indicate if changes were made.

\section{References}

Aldrich, John H. (1993). Rational choice and turnout. American Journal of Political Science, 37(1), 246-278.

Angrist, J. D., \& Pischke, J. S. (2008). Mostly harmless econometrics: An empiricist's companion. New Jersey: Princeton University Press.

\footnotetext{
${ }^{16}$ For another example of divergence between U.S. and European results, Bhatti et al. (2016) paper finds canvassing, usually considered the most effective tool in U.S. GOTV studies, is largely ineffective in Europe.
} 
Arceneaux, K., \& Nickerson, D. W. (2009). Who is mobilized to vote? A re-analysis of 11 field experiments. American Journal of Political Science, 53(1), 1-16.

Bergh, J., \& Bjørklund, T. (2010). Political integration of minorities: Election turnout in Norway's minority communities. In B. Bengtsson, P. Strömblad, \& A. H. Bay (Eds.), Diversity, inclusion and citizenship in Scandinavia, Newcastle upon Thyne. UK: Cambridge Scholars Publishing.

Bergh, J., Christensen, D. A., \& Matland, R. (2016). Getting out the vote. Experiments in voter mobilization among immigrants and natives in Norway (p. 12). Oslo: Institute for social research, Report.

Bhatti Y, Dahlgaard JO, Hansen JH, Hansen KM (2014) Kan man øge valgdeltagelsen? Analyse af mobiliseringstiltag ved kommunalvalget den 19. November 2013. CVAP Working Paper Series, Copenhagen

Bhatti, Y., Dahlgaard, J. O., Hansen, J. H., \& Hansen, K. M. (2016). Is door-to-door canvassing effective in Europe? Evidence from a meta-study across six European countries. British Journal of Political Science, 2016(1), 1-12.

Bhatti, Y., Dahlgaard, J. O., Hansen, J. H., \& Hansen, K. M. (2017). Moving the campaign from the front door to the front pocket: Field experimental evidence on the effect of phrasing and timing of text messages on voter turnout. Journal of Elections, Public Opinion and Parties, 27(3), 291-310.

Dale, A., \& Strauss, A. (2009). Don't forget to vote: Text message reminders as a mobilization tool. American Journal of Political Science, 53(4), 787-804.

Enos, R. D., Fowler, A., \& Vavreck, L. (2014). Increasing inequality: The effect of GOTV mobilization on the composition of the electorate. The Journal of Politics, 76(01), 273-288.

Garcia Bedolla, L., \& Michelson, M. R. (2012). Mobilizing inclusion: Transforming the electorate through get-out-the-vote campaigns. New Haven: Yale University Press.

Gerber, A. S., \& Green, D. P. (2012). Field experiments: Design, analysis, and interpretation New York. NY: WW Norton.

Green, D. P., \& Gerber, A. S. (2015). Get out the vote! (3rd ed.). Washington, D.C.: Brookings Institution.

Green, D. P., McGrath, M. C., \& Aronow, P. M. (2013). Field experiments and the study of voter turnout. Journal of Elections, Public Opinion \& Parties, 23(1), 27-48.

Malhotra, N., Michelson, M. R., Rogers, T., \& Valenzuela, A. A. (2011). Text messages as mobilization tools: The conditional effect of habitual voting and election salience. American Politics Research, 39(4), 664-681.

Matland, R. E., \& Murray, G. R. (2012). An experimental test of mobilization effects in a Latino community. Political Research Quarterly, 65(1), 192-205.

Michelson, M. R., \& Nickerson, D. W. (2011). Voter mobilization (p. 228). Cambridge: Handbook of Experimental Political Science.

Mjelde, H. L., Folkestad, B., Aars, J., \& Christensen, D. A. (2015). The 2015 Norwegian local elections: Support for governing radical right progress party plummets and great gains for greens in 'secondorder' elections. Regional and Federal Studies, 26(2), 243-253.

Murray, G. W., \& Matland, R. E. (2014). Mobilization effects using mail: Social pressure, invoking injunctive norms and timing. Political Research Quarterly, 67(2), 304-319.

Nickerson, D. W. (2006). Volunteer phone calls can increase turnout evidence from eight field experiments. American Politics Research, 34(3), 271-292.

Panagopoulos, C. (2011). Timing is everything? Primacy and recency effects in voter mobilization campaigns. Political Behavior, 33(1), 79-93.

Statistics Norway (SSB). (2016). Municipal and county election, electoral survey. Oslo: SSB.

Thaler, R. H., \& Sunstein, C. (2009). Nudge: Improving decisions about health, wealth, and happiness. London: Penguin Books.

Zaller, J. R. (1992). The Nature and Origins of Mass Opinion. Cambridge: Cambridge University Press.

Publisher's Note Springer Nature remains neutral with regard to jurisdictional claims in published maps and institutional affiliations. 